\title{
Elasticity of Substitution in Post-Communist Economies
}

\author{
Karol Szomolányi \\ University of Economics Bratislava, Slovakia \\ Martin Lukáčik \\ University of Economics Bratislava, Slovakia \\ Adriana Lukáčiková \\ University of Economics Bratislava, Slovakia
}

\begin{abstract}
In our research we estimate the elasticity of substitution post-communist economies integrated in European Union. There are many approaches to estimate the production function coefficients as the elasticity of substitution. We argue that a frequency panel model is suitable econometric tool for our purposes. We derive the specification from the capital demand first-order condition of firm maximising its profit. Data are adapted from the World Penn Tables and World Development Indicators, World Bank. Data are modified with band-pass filter to abstract them from the business cycles and the short-term effects driven by different underlying processes. The filter creates overlapping observations, the stochastic term is serially correlated and therefore feasible generalized least squares estimator is used. Comparing the results with the relevant results in a world literature we estimate relatively low value of the elasticity of substitution in European post-communist countries. Possible explanations are discussed.
\end{abstract}

Keywords: elasticity of substitution, European post-communist countries, panel model JEL classification: C23, E22, E25

Acknowledgments: The Grant Agency of Slovak Republic - VEGA, supports this paper by grant no. 1/0294/18, "Short-run and long-run dynamic analysis of economic development of European post-communist countries and regions".

\section{Introduction}

Contemporary economic issues focus in the importance of the production function parameters. Chirinko et al. (2014) highlight the importance with the rich literature review.

There are many approaches of the estimation of production function coefficients. We refer Klump et al. (2012) and Chirinko (2008) for the short surveys. All approaches use three econometric forms derived from the CES production function linearization, capital and labour demand of the firm maximizing its profit However, modern theoretical claims highlight the importance of the production function normalization (see Klump et al. (2012) or Chirinko et al. (2014) for more discussion).

Considering the theoretic and econometric claims and after enormous study of all approaches we acknowledge only two of them; Klump et al. (2007) and Chirinko et al. (2014). Klump et al. (2007) estimated the system of equations consisting of the CES production function linearization and two first-order conditions of a firm maximising its 
profit. Authors accentuate the production function normalisation and a biased technological change concept.

Chirinko et al. (2014) propose an approach of the coefficient of the elasticity of the substitution estimation dealing with the first-order condition of the firm maximising its profit corresponding to the capital. Authors modify their data series by the bandpass filter to abstract them from the business cycles and the short-term effects driven by different underlying processes. They prove that the approach meets the production function normalisation and they observe that considering a biased technological change does not affect the result of the estimated elasticity of substitution. Finally they observe that the method can be used for aggregate data.

Both studies estimate low value of the elasticity of substitution in the U.S. economy: 0.60 by Klump et al. (2007) and 0.40 by Chirinko et al. (2014). The literature review of the past empirical studies estimating the production function coefficients is provided by Chirinko (2008) or Klump et al. (2012).

In the paper, we choose the approach of Chirinko et al. (2014) to estimate elasticity of substitution in post-communist economies integrated to the European Union. The panel-data concept is suitable for post-communist countries with the limited small databases.

\section{Model}

Consider the constant elasticity of substitution production function in the form:

$$
Y_{i t}=A_{i t}\left[\alpha_{i}\left(\kappa_{i} K_{t}\right)^{\frac{\sigma-1}{\sigma}}+\left(1-\alpha_{i}\right)\left(v_{i} N_{t}\right)^{\frac{\sigma-1}{\sigma}}\right]^{\frac{\sigma}{\sigma-1}}
$$

where inputs are capital and labour, $K_{\text {it }}$ and $N_{\text {it }}$ (for each period $t$ and each country i), the symbol $0<a_{i}<1$ is the share parameter of each country, by symbol $\sigma>0$, we denote the elasticity of substitution and $A_{i t}$ is the total factor productivity parameter. The parameters $K_{i}$ and $v_{i}$ are normalisation parameters (see Klump et al.; 2012). The special cases of the production function are if $\sigma \rightarrow 0$, the inputs are not substitutable, if $\sigma \rightarrow 1$, then the production function is Cob-Douglass, if $\sigma \rightarrow \infty$, then the production function is linear and the inputs are perfectly substitutable.

To derive the estimation form describing the capital demand we derive the relationships between (logs of) marginal and average products (MPK $t_{t}$ and $\left.A P K_{t}\right)$ of the capital in the form:

$$
\log \left(M P K_{i t}\right)=\log \left(1-\alpha_{i}\right)+\frac{\sigma-1}{\sigma} \log \left(\kappa_{i}\right)+\frac{\sigma-1}{\sigma} \log \left(A_{i t}\right)+\frac{1}{\sigma} \log \left(A P K_{i t}\right)
$$

The firm is maximizing its profit, if his marginal product of capital equals to the capital price/output ratio. The estimation form derived from the first-order condition of the firm can be written as follows:

$$
y_{t}=\beta_{0 i}+\beta_{1} x_{i t}+u_{i t}
$$

where $y_{i t}$ corresponds to the capital/output ratio, $x_{i t}$ corresponds to its relative prices (capital price/output price ratio). To fit the formula with the first-order condition of the firm, both variables are measured by their natural logarithms. To eliminate the effects of different underlying economic processes, ensuring the exogeneity of the 
price ratio $x_{i t}$, both variables are measured by the proper long-run values. The stochastic term is Uit. As Chirinko et al. (2014) argue, these values can be reached using band-pass filter. The elasticity of substitution is the negative value of the $\beta_{1}$ coefficient, i.e. $\sigma=-\beta_{\text {l. }}$.

Note that the elasticity of substitution is independent on the normalisation parameters $k$ and $v$. Considering the first-order condition of the firm we have solved the normalisation problem.

\section{Methodology}

The band-pass filters are used to isolate the cyclical component of a time series by specifying a range for its duration. These filters are linear filters that takes a two-sided weighted moving average of the data where cycles in a "band", given by a specified lower and upper bound, are "passed" through, or extracted, and the remaining cycles are "filtered" out.

On the contrary, our goal is to obtain a non-cyclical component of a time series; therefore, our task is reversed compared to the classical extraction of the cyclical component. We decided to use Baxter et al. (1999) band-pass filter, because their band-pass filter is more flexible and easier to implement than other filters, while producing a better approximations to the ideal filter.

Panel data is a type of pooled data in which the same cross-sectional unit (in our case post-communist countries) is surveyed over time. Baltagi (2013) lists several advantages of panel data. We prefer that panels give data that are more informative, give more variability, less collinearity among the variables, more degrees of freedom, and more efficiency.

The simplest model of pooled regression (Pool) disregard the space and time dimensions of the pooled data and just estimate the OLS regression:

$$
y_{i t}=\beta_{0}+\beta_{1} x_{1 i t}+\beta_{2} x_{2 i t}+\beta_{k} x_{k i t}+u_{i t}
$$

The model assumes that the intercept and slope coefficients are constant across time and space and the error term captures differences over time and individuals.

If we assume that, the slope coefficients are constant but the intercept varies over individuals:

$$
y_{i t}=\beta_{0 i}+\beta_{1} x_{1 i t}+\beta_{2} x_{2 i t}+\beta_{k} x_{k i t}+u_{i t}
$$

the slope coefficients are constant but the intercept varies over time:

$$
y_{i t}=\beta_{0 t}+\beta_{1} x_{1 i t}+\beta_{2} x_{2 i t}+\beta_{k} x_{k i t}+u_{i t}
$$

the slope coefficients are constant but the intercept varies over individuals and time:

$$
y_{i t}=\beta_{0 i t}+\beta_{1} x_{1 i t}+\beta_{2} x_{2 i t}+\beta_{k} x_{k i t}+u_{i t}
$$

our choice is the fixed effects model (FEM) or so-called Least-Squares Dummy Variable (LSDV) regression model. In this type of model, we can use also slope dummies to account for differences in slope coefficients of cross-sectional units.

We can test the justification for using FEM model versus Pool model by $F$ test. It is test of the joint significance of all of the effects as well as the joint significance of the 
cross-section effects and the period effects separately. Test is explained in Greene (2012).

Instead of treating $\beta_{0 i}$ in (5) as fixed, we can assume that it is a random variable with a mean value of $\beta$. Moreover, the intercept value for an individual cross section unit can be expressed as:

$$
\beta_{0 i}=\beta_{0}+\varepsilon_{i}
$$

where $\varepsilon_{i}$ is a random error term. Substituting (8) into (5), we obtain:

$$
y_{i t}=\beta_{0}+\beta_{1} x_{1 i t}+\beta_{2} x_{2 i t}+\beta_{k} x_{k i t}+\varepsilon_{i}+u_{i t}
$$

The composite error term consists of two components, $\varepsilon_{i}$ which is the cross-section, or individual-specific, not directly observable error component, and Uit, which is the combined time series and cross-section error component. The model (9) is called the random effects model (REM). The most appropriate method of estimation here is the method of generalized least squares (GLS).

The central assumption in random effects estimation is the assumption that the random effects are uncorrelated with the explanatory variables. One common method for testing this assumption is to employ a Hausman test to compare the fixed and random effects estimates of coefficients. Test is explained in Greene (2012).

If we have to deal with autocorrelation or heteroskedasticity of residuals in our models, we have to change estimation method on feasible generalized least squares (EGLS) estimator. Specialized programs designed for econometrics offer different types of weight for this method. We can also specify a method for computing coefficient covariances. Specialized programs offer various robust methods available for computing the coefficient standard errors. The covariance calculations may be chosen to be robust under various assumptions.

\section{Data}

Data of 11 post-communist countries integrated to the European Union are gathered from the Penn World Tables Database (Feenstra et al., 2015) and World Development Indicators, World Bank. The studied countries are Bulgaria, Czech Republic, Estonia, Croatia, Hungary, Lithuania, Latvia, Poland, Romania, Slovakia and Slovenia.

Real output (GDP) and capital in national currency units is measured by the dataseries gathered from the Penn World Tables Database. The GDP deflator gathered from the Penn World Tables Database measures output price. We used the process from León-Ledesma et al. (2010) to measure capital user costs (i.e. capital price). The nominal user cost is defined as the product of the investment deflator and the real user cost, the latter being the sum of real interest rate and the depreciation rate, where investment deflator and interest rate is gathered from the Penn World Tables Database. Real interest rates are measured by lending interest rate gathered from the World Development Indicators, World Bank.

Capital/output ratio and its relative prices are modified by band-pass filter suggested by Baxter et al. (1999). We used the frequency respond function and experiments with various selections of lags and leads and periodicity to find that Baxter and King's suggested selection of 3 year lags and leads, 2 year low and 8 year high cycle period is proper. After filtering we lost first 3 and last 3 observations. 
We tried to use the longest dataset possible, however the dataset of interest rates are limited. After band-filter adjustment our dataset consisted of 150 observations.

\section{Results}

Since the band-pass filter creates overlapping observations, the stochastic term is serially correlated and therefore EGLS is proper estimator of (3). Below is the estimated form:

$$
\begin{array}{r}
\hat{y}_{i t}=1.791-0.159 x_{i t} \\
(0.200)(0.080)
\end{array}
$$

The estimated value of elasticity of substitution in chosen post-communist countries is 0.159 and it is statistically significant at the $5 \%$ level. This value is relatively very small in comparison with the estimates realised by Chirinko et al. (2014) using the same method and U.S. data.

We tried to repeat the experiment with a dataset consisting of more homogenous countries. Therefore, we estimated (3) considering Visegrád Group (Czech Republic, Hungary, Poland and Slovakia), Croatia and Slovenia (V4+2; with 76 observations):

$$
\begin{aligned}
\hat{y}_{i t}= & 2.030-0.259 x_{i t} \\
& (0.094)(0.040)
\end{aligned}
$$

and considering only Visegrád Group (V4; with 49 observations) we estimated:

$$
\begin{gathered}
\hat{y}_{i t}=2.248-0.360 x_{i t} \\
(0.094)(0.039)
\end{gathered}
$$

Estimate (11) corresponds to the V4+2 dataset, while estimate (12) corresponds to the V4 dataset. All coefficients are statistically significant at the $1 \%$ level. Note that the estimated elasticity of substitution increased ( 0.259 and 0.360 respectively), but the values are still relatively low.

The justification for using FEM was tested and rejected in all cases.

\section{Discussion}

Comparing our results with the novel estimates around the world, the elasticity of substitution in post-communist countries are relatively low. However, the reviews of other empirical papers provided by Chirinko (2008) and Klump et al. (2012) admit such low values.

Jürgen (2009) provide a possible explanation of low elasticity of substitution in transition post-communist countries. Using a theoretical model with microfoundations he assumes a lower elasticity of substitution in transition economy. We assume that European post-communist countries have been in the transition state in the study period. Using neoclassical growth conceptual schema, all events characteristic for European post-communist countries like the transition from central planned economy to the market economy, opening to the western European markets, entrancing to the European monetary Union, labour tax reforms have changed the steady state and have started a transition move to its new steady 
state. Another empirical confirmation of this theory comes from our previous estimation of elasticity of substitution, i.e. Szomolányi et al. (2017). The estimated value of Slovak elasticity of substitution using dataset gathered from the National bank of Slovakia is relatively low as well.

Our study opens other questions. Is Jürgen's (2009) hypothesis of the dual elasticity of substitution in transition and steady state relevant? Can this concept re-explain the neoclassical growth theory? Answering these questions would be helpful for the policymakers in European post-communist countries in transition state.

The limitation of our study is small dataset; however this limitation comes from the fact that published interest rate data series corresponding to the European postcommunist countries are poor.

\section{Conclusion}

The elasticity of substitution in post-communist countries integrated to European Union is relatively small. This information is surely helpful for policymakers in these countries. The elasticity of substitution values is informative for the redistribution purposes. The effect of tax cuts is lower the lower is elasticity of substitution.

Moreover, the low elasticity of substitution has an impact on economic analysis. As Chirinko et al. (2014) state, low value of the elasticity of substitution suggests that "the convenient and all too often conventional assumption of a Cobb-Douglas production function used in many areas of economic analysis needs to be abandoned."

\section{References}

1. Baltagi, B. H. (2013), Econometric Analysis of Panel Data (5th edition), John Wiley and Sons, New York.

2. Baxter, M., King, R. G. (1999), "Measuring Business Cycles: Approximate Band-Pass Filters for Economic Time Series", The Review of Economics and Statistics, Vol. 81, No. 4, pp. 575-593.

3. Chirinko, R. S. (2008), " $\sigma$ : The long and short of it", Journal of Macroeconomics, Vol. 30 , No. 2, pp. 671-686.

4. Chirinko, R. S., Mallick, D. (2014), "The Substitution Elasticity, Factor Shares, Long-Run Growth, and the Low-Frequency Panel Model", Working Paper No. 4895, CESifo Group Munich, December 2015.

5. Feenstra, R. C., Inklaar, R., Timmer, M. P. (2015). "The Next Generation of the Penn World Table", American Economic Review, Vol. 105, No. 10, pp. 3150-3182.

6. Greene, W. H. (2012), Econometric Analysis (7th edition), Pearson, New Jersey.

7. Jürgen, A. (2009), "A Dual Elasticity of Substitution Production Function with an Application to Cross Country Inequality", Economics Letters, Vol. 102, No.1, pp. 10-12.

8. Klump, R., McAdam, P., Willman, A. (2007), "Factor Substitution and Factor Augmenting Technical Progress in the US", The Review of Economics and Statistics, Vol. 89, No.1, pp. 183-192.

9. Klump, R., McAdam, P., Willman, A. (2012), "The Normalized CES Production Function: Theory and Empirics", Journal of Economic Surveys, Vol. 26, No. 5, pp. 769-799.

10. León-Ledesma, M.A., McAdam, P., Willman, A. (2010). "In Dubio pro CES: Supply Estimation with Mis-Specified Technical Change", Working Paper No. 1175, European Central Bank, April 2010.

11. Szomolányi, K., Lukáčiková, A., Lukáčik, M. (2017), "Long-Run Elasticity of the Substitution in the Slovak Economy", in Proceeding of ENTRENOVA conference, 7-9 September, Dubrovnik, Croatia. 


\section{About the authors}

Karol Szomolányi was born in Bojnice in the Slovak Republic (formerly Czechoslovakia) in 1976. He is an associated professor of operations research and econometrics at University of Economics in Bratislava, Faculty of Economic Informatics, Department of Operations Research and Econometrics. He is a member of the Slovak Society for Operations Research. He deals with the macroeconomic analysis and econometrics. His areas of interest are real business cycle models and dynamic stochastic macroeconomic models and their use for developing countries of Eastern Europe. The author can be contacted at karol.szomolanyi@euba.sk.

Martin Lukáčik was born in Žilina in the Slovak Republic (formerly Czechoslovakia) in 1974. He is an associated professor of operations research and econometrics at University of Economics in Bratislava, Faculty of Economic Informatics, Department of Operations Research and Econometrics. He is a president of the Slovak Society for Operations Research. He deals with the econometric methods in macroeconomic framework and time series econometrics. His areas of interest are VAR models used in macroeconomics and forecasting methods. The author can be contacted at martin.lukacik@euba.sk.

Adriana Lukáčiková was born in Gelnica in the Slovak Republic (formerly Czechoslovakia) in 1971. She is an assistant professor of operations research and econometrics at University of Economics in Bratislava, Faculty of Economic Informatics, Department of Operations Research and Econometrics. She is a member of the Slovak Society for Operations Research. She deals with the computable general equilibrium models and econometrics. Her area of interest is econometric modelling of national economy. The author can be contacted at adriana.lukacikova@euba.sk. 